\title{
Evidence based cardiovascular risk assessment: role of global risk scoring, biomarkers and subclinical disease evaluation
}

\author{
Nathan D. Wong, PhD, FACC, FAHA \\ Heart Disease Prevention Program, Division of Cardiology, \\ University of California, Irvine, California, USA
}

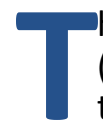
he accurate evaluation of cardiovascular disease (CVD) risk in asymptomatic adults is a challenging task. While a basic medical history and standard laboratory tests can provide a rough estimate of risk factor burden, such an estimate is only a rough approximation of risk as many persons suffering CVD events do not necessarily have multiple risk factors, and conversely many who do have multiple risk factors will never suffer a CVD event. In order to best identify asymptomatic persons at risk for future cardiovascular disease (CVD) events, it is important to understand the guidelines for CVD risk assessment and evidence-based methods for evaluation of risk in asymptomatic individuals.

In this review, we will 1) discuss the role and limitations of global risk assessment, 2) review the evidence and recommendations for biomarkers in CVD risk assessment, and 3) review the evidence and recommendations for subclinical disease evaluation / imaging in CVD risk assessment.

\section{Global risk assessment}

In 1961, Dr. William B. Kannel, a former director of the Framingham Heart Study, the longest running epidemiologic study of cardiovascular disease which began in 1948, introduced the concept of cardiovascular risk factors from some of the early longitudinal data of the study showing the importance of elevated cholesterol, blood pressure, and smoking in relation to future coronary heart disease (CHD) risk ${ }^{1}$.

The concepts of multivariable and global risk assessment, based on estimating risk from the combination of several risk factors (Figure 1) evolved over succeeding decades. Here a direct relation between the number of $\mathrm{CHD}$ risk factors present and the cumulative risk of $\mathrm{CHD}$ was demonstrated. This further resulted in the development of the Framingham Risk Scores beginning in 1991, as well as other risk scores used in other parts of the world, including the SCORE algorithms in Europe (2-4), which all differ ac- cording to the endpoint used, length of follow-up, and risk factors included. The US National Cholesterol Education Program (NCEP) in 2001 recommended the use of global risk assessment scoring specifically for persons at suggested intermediate risk based on the presence of 2 or more risk factors including age $>45$ years in a male or $>55$ in a female, hypertension, low HDL-C, current cigarette smoking, and a positive family history of premature CHD, and involving the calculation of 10 -year risk of hard $\mathrm{CHD}$ defined a nonfatal myocardial infarction or CHD death ${ }^{5}$. However, measures of obesity, physical inactivity, or family history were not included in the Framingham risk algorithms and the NCEP 2001 algorithm designated diabetes a CHD risk equivalent, so this was not included as well. For example, one can apply different risk scoring systems to a given case study, a 67-year old woman, non-smoker, with total cholesterol of $210 \mathrm{mg} / \mathrm{dl}$, systolic blood pressure of 138 $\mathrm{mmHg}$, and HDL-cholesterol of $42 \mathrm{mg} / \mathrm{dl}$. She also has a triglyceride level of $201 \mathrm{mg} / \mathrm{dl}$, waist circumference of 36 inches, and fasting glucose of $109 \mathrm{mg} / \mathrm{dl}$ which do not factor into these risk scores, but show that she has all five metabolic syndrome risk factors. Depending on what risk score is used, one gets dramatically different results, ranging from only 1-2\% of the European SCORE algorithm for fatal CVD is used, to $3 \%$ if the 10-year hard CHD Framingham risk score is used (6), 10\% if the Framingham 10-year total CVD risk score is used, to $39 \%$ if lifetime risk is estimated. While many physicians might suggest she is at high risk on the basis of having all five metabolic syndrome risk factors, the wide estimates in risk obtained demonstrate that the degree and severity of risk factors plays an important role in risk estimation as does the endpoint (CHD vs. CVD) and duration (10-year vs. 30-year or lifetime) of risk of interest.

Many persons who suffer CVD events are not at high risk; in fact, $56 \%$ or 87 million persons in the US have low short-term but high lifetime risk ${ }^{7}$ and lifetime risk for total CVD is approximately $60 \%$ in men and $50 \%$ in women ${ }^{8}$. 


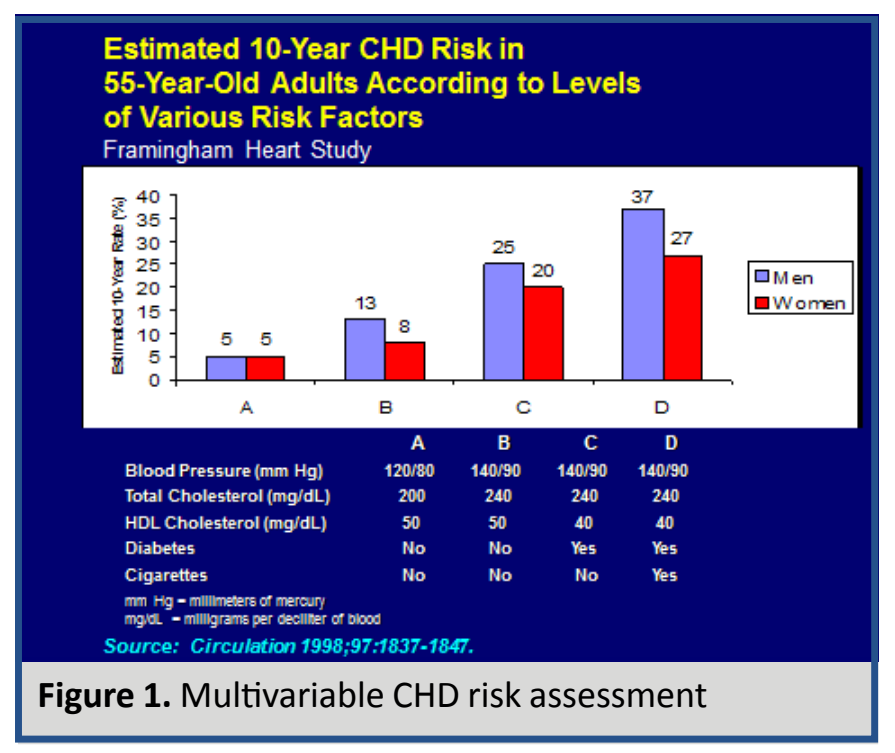

\section{Criteria for assessing the performance of newer screening tests}

Global risk scoring algorithms are therefore only moderate accurate for identifying those who will eventually suffer a major coronary event. There are a number of criteria that are required for a good screening test for evaluation of CVD risk. These criteria include sensitivity in identifying those who have the condition of interest, providing reproducible results, detecting those where early intervention is likely to have a beneficial impact, and being able to provide incremental value to risk predicted by office-based risk assessment (eg., risk scores) ${ }^{9}$. While multivariable regression analyses can identify whether a particular new measure predicts outcomes independently of standard risk factors and/or other measures, the performance of a new test against or in addition to a standard set of risk factors or global risk score (e.g., office-based risk assessment) can be better examined by comparing the $\mathrm{C}$-statistic obtained from receiver operator curve (ROC) analyses. While this test has often been criticized for being overly conservative, it does provide the ability to statistically compare models with or without the addition of a new test of interest. Standard risk factors alone or a global risk score will often

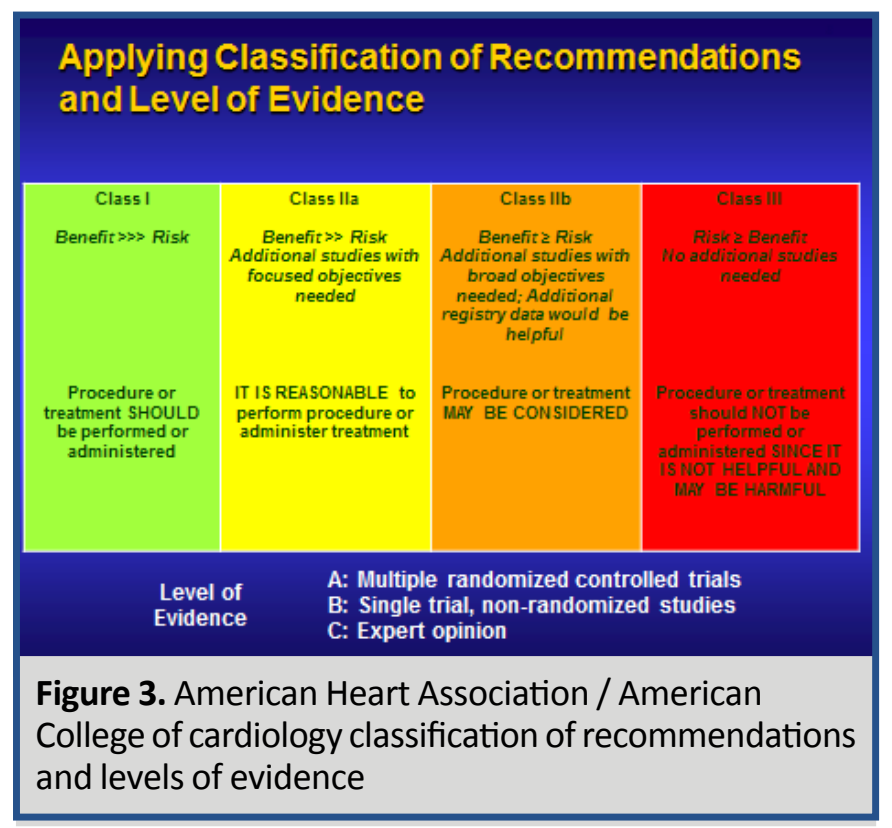

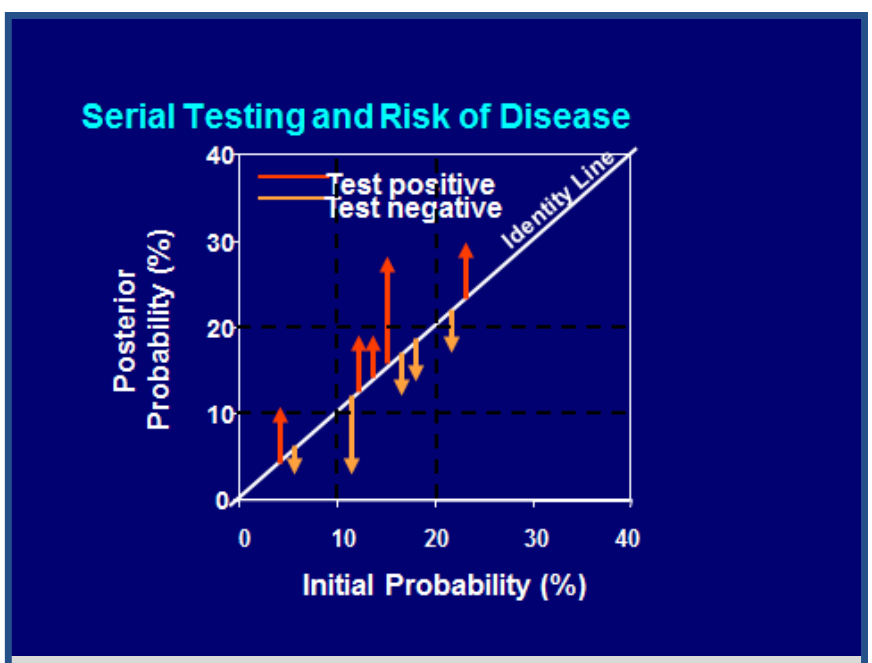

Figure 2. Reclassification of risk by a screening test

provide a C-statistic in the range of $0.65-0.70$ and most biomarkers or screening tests will increase this modestly to $0.70-0.80$, with statistical significance depending on the degree of increase in C-statistic and sample size.

A screening test can be applied to those initially at intermediate (e.g., 10-20\%) risk and if positive, would stratify that person to a higher risk category, and if negative would stratify them to a lower risk category (Figure 2). A new metric for clinical utility, the net reclassification index, is defined as the net proportion of persons who are correctly reclassified from the new test, or the sum of 1) cases whose risk is stratified upward (correct) by the test being positive minus the cases where risk is stratified downward (incorrect) and 2) controls whose risk is stratified downward (correct) minus those who are stratified upward (incorrect) $)^{10}$. This measure requires a clear definition of cutpoints for defining boundaries for low, intermediate, and high risk and positivity of a test.

In 2010, the American College of Cardiology Foundation (ACCF) / American Heart Association (AHA) guidelines for CVD risk assessment in asymptomatic adults were published and forms the basis for the recommendations and screening tests discussed in this report ${ }^{2}$. They graded a large number of screening tests according to the

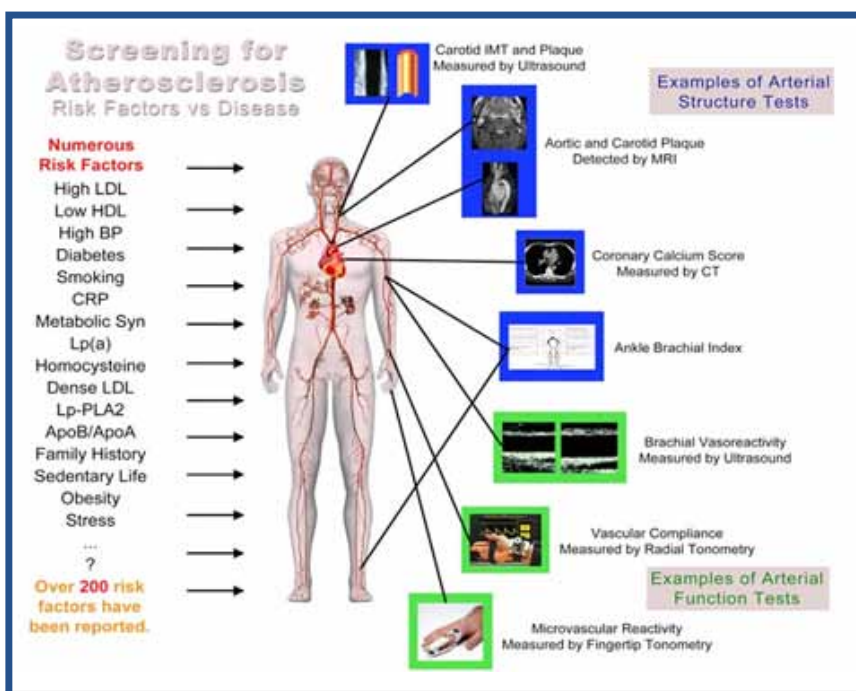

Figure 4. Screening tests for subclinical cardiovascular disease 
Table 1. Recommendations for cardiovascular risk assessment in asymptomatic adults, adapted from greenland et al. ${ }^{2}$

\begin{tabular}{|c|c|c|}
\hline Measurement & Recommendation & $\begin{array}{l}\text { AHA/ACC Classification of Recommendation } \\
\text { and Level of Evidence }\end{array}$ \\
\hline Global Risk Scoring & $\begin{array}{l}\text { Should be obtained in all asymptomatic adults without } \\
\text { a clinical history of CHD }\end{array}$ & I-B \\
\hline Family History & $\begin{array}{l}\text { Should be obtained for cardiovascular risk assessment } \\
\text { in all asymptomatic adults }\end{array}$ & I-B \\
\hline Genomic Testing & $\begin{array}{l}\text { Genotype testing for CHD risk assessment is not rec- } \\
\text { ommended for asymptomatic adults }\end{array}$ & III-B \\
\hline $\begin{array}{l}\text { Lipoprotein and } \\
\text { Apolipoprotein } \\
\text { Assessments }\end{array}$ & $\begin{array}{l}\text { Measurement of lipid parameters, including lipo- } \\
\text { proteins, apolipoproteins, particle size, and desntiy, } \\
\text { beyond a standard fasting lipid profile is not recom- } \\
\text { mended for cardiovascular risk assessment }\end{array}$ & III-C \\
\hline Natriuretic Peptides & $\begin{array}{l}\text { Measurement not recommended for CHD risk assess- } \\
\text { ment in asymptomatic adults }\end{array}$ & III-B \\
\hline C-reactive Protein & $\begin{array}{l}\text { Men aged } 50 \text { and over or women aged } 60 \text { and over } \\
\text { with } L D L-C<130 \mathrm{mg} / \mathrm{dl} \text { without } \mathrm{CHD} \text { or inflammatory } \\
\text { conditions } \\
\text { Asymptomatic intermediate risk men }<=50 \text { years or } \\
\text { women }<=60 \text { years } \\
\text { Not recommended for high risk adults or those at low } \\
\text { risk }<50 \text { years in men or }<60 \text { years in women. }\end{array}$ & $\begin{array}{l}\text { Ila-A } \\
\text { IIb-B } \\
\text { III-B }\end{array}$ \\
\hline Hemoglobin A1c & $\begin{array}{l}\text { Measurement reasonable for cardiovascular risk as- } \\
\text { sessment in asymptomatic adults with or without } \\
\text { diabetes }\end{array}$ & IIb-B \\
\hline Microalbuminuria & $\begin{array}{l}\text { Measurement reasonable for cardiovascular risk as- } \\
\text { sessment in asymptomatic adults with hypertension } \\
\text { or diabetes } \\
\text { Measurement reasonable in those at intermediate risk } \\
\text { without hypertension or diabetes }\end{array}$ & $\begin{array}{l}\text { Ila-B } \\
\text { Illb-B }\end{array}$ \\
\hline $\begin{array}{l}\text { Lipoprotein- } \\
\text { Associated } \\
\text { Phospholipase A2 }\end{array}$ & $\begin{array}{l}\text { Measurement reasonable for cardiovascular risk as- } \\
\text { sessment in intermediate-risk asymptomatic adults }\end{array}$ & IIb-B \\
\hline $\begin{array}{l}\text { Resting } \\
\text { Electrocardiogram }\end{array}$ & $\begin{array}{l}\text { Reasonable for risk assessment in asymptomatic } \\
\text { adults with hypertension or diabetes } \\
\text { May be considered for cardiovascular risk assessment } \\
\text { in asymptomatic adults without hypertension or dia- } \\
\text { betes }\end{array}$ & $\begin{array}{l}\text { Ila-C } \\
\text { IIb-C }\end{array}$ \\
\hline
\end{tabular}

strength of recommendation or size of effect (Class I being strongest indicating the test or intervention should be performed, Class lla where it is reasonable to perform the test or intervention, IIb where the test or intervention may be considered, to Class III being weakest indicating the test or intervention should not be performed) and level of evidence (A being strongest and $C$ being weakest) (Figure 3). Table 1 shows a summary of the recommendations for different risk assessment strategies ranging from global risk scoring to biomarkers to subclinical CVD assessment, with several key modalities discussed below.

\section{Inflammatory factors and other biomarkers}

The potential role of inflammatory and other biomarkers for the prediction of initial and recurrent CVD events has been an active area of investigation for nearly two decades. Much of this interest was prompted initially by the numerous prospective studies documenting high sensitivity C-reactive protein to be an independent risk factor for CVD events with approximately a two to four-fold greater risk associated with being in the highest vs. lowest quartile ${ }^{11}$. These studies, as well as the JUPITER clinical trial involving rosuvastatin given to persons with normal LDL-C but elevated hs-CRP resulting in significant CVD event reduction, have led to the hs-CRP recommendations from the ACCF/AHA statement and the National Lipid Association expert panel. They do recommend (Class Ila or Ilb, level of evidence B) hs-CRP assessment in men aged 50 years or over or women aged 60 years and over not on lipid-lowering therapy but with an LDL-C $<130 \mathrm{mg} /$ $\mathrm{dl}$, as well as younger intermediate risk persons. Measurement, however, is not recommended in higher or lower risk persons ${ }^{2}$. Moreover, while some studies do show hs-CRP to provide incremental clinical utility for risk assessment over risk factors, this is not a universal finding and adoption of routine testing of hs-CRP by clinicians still remains limited. A finding of an elevated hs-CRP level has been best utilized to provide the impetus for starting preventive therapies, particularly statins, when patient risk and LDL-C levels are insufficient to otherwise provide a convincing case for such therapy.

Elevated levels of lipoprotein associated phospholipase $\mathrm{A} 2\left(\mathrm{LpPla}_{2}\right)$ are also shown from a large meta-analysis to confer excess risk of CVD events, and to provide 


\begin{tabular}{|c|c|c|}
\hline $\begin{array}{l}\text { Transthoracic } \\
\text { Echocardiography }\end{array}$ & $\begin{array}{l}\text { May be considered for cardiovascular risk assessment } \\
\text { in asymptomatic adults with hypertension } \\
\text { Not recommended for cardiovascular risk assessment } \\
\text { in asymptomatic adults without hypertension }\end{array}$ & IIIb-B \\
\hline $\begin{array}{l}\text { Carotid Intima-Media } \\
\text { Thickness }\end{array}$ & $\begin{array}{l}\text { Measurement reasonable for cardiovascular risk assess- } \\
\text { ment in asymptomatic adults at intermediate risk }\end{array}$ & Ila-B \\
\hline $\begin{array}{l}\text { Brachial/Peripheral } \\
\text { Flow-Mediated } \\
\text { Dilation }\end{array}$ & $\begin{array}{l}\text { Not recommended for cardiovascular risk assessment } \\
\text { in asymptomatic adults }\end{array}$ & III-B \\
\hline $\begin{array}{l}\text { Measures of Arterial } \\
\text { Stiffness }\end{array}$ & $\begin{array}{l}\text { Not recommended for cardiovascular risk assessment } \\
\text { in asymptomatic adults }\end{array}$ & III-C \\
\hline Ankle-Brachial Index & $\begin{array}{l}\text { Measurement reasonable for cardiovascular risk assess- } \\
\text { ment in asymptomatic adults at intermediate risk }\end{array}$ & Ila-B \\
\hline $\begin{array}{l}\text { Exercise } \\
\text { Electrocardiography }\end{array}$ & $\begin{array}{l}\text { May be considered for cardiovascular risk assessment } \\
\text { in intermediate-risk asymptomatic adults }\end{array}$ & IIb-B \\
\hline $\begin{array}{l}\text { Stress } \\
\text { Echocardiography }\end{array}$ & $\begin{array}{l}\text { Not indicated for cardiovascular risk assessment in } \\
\text { low-or intermediate-risk asymptomatic adults }\end{array}$ & III-C \\
\hline $\begin{array}{l}\text { Myocardial Perfusion } \\
\text { Imaging }\end{array}$ & $\begin{array}{l}\text { May be considered for advanced cardiovascular risk } \\
\text { assessment in asymptomatic adults with diabetes or a } \\
\text { strong family history of CHD or when previous risk as- } \\
\text { sessment suggests a high risk of CHD, such as a coro- } \\
\text { nary calcium score >=400 } \\
\text { Not indicated for cardiovascular risk assessment in } \\
\text { low-or intermediate-risk asymptomatic adults }\end{array}$ & IIb-C \\
\hline Calcium Scoring & $\begin{array}{l}\text { Measurement reasonable for cardiovascular risk as- } \\
\text { sessment in asymptomatic adults at intermediate risk } \\
\text { (10-20\% 10-year risk) or in those with diabetes aged } \\
40 \text { years and over } \\
\text { Measurement reasonable for cardiovascular risk as- } \\
\text { sessment in persons at low to intermediate risk (6- } \\
10 \% 10 \text {-year risk) } \\
\text { Not recommended for measurement in persons at low } \\
(<10 \% 10 \text {-year risk) risk }\end{array}$ & $\begin{array}{l}\text { IIb-B } \\
\text { III-B }\end{array}$ \\
\hline $\begin{array}{l}\text { Coronary Computed } \\
\text { Tomography } \\
\text { Angiography }\end{array}$ & $\begin{array}{l}\text { Not recommended for cardiovascular risk assessment } \\
\text { in asymptomatic adults }\end{array}$ & III-C \\
\hline $\begin{array}{l}\text { Magnetic Resonance } \\
\text { Imaging of Plaque }\end{array}$ & $\begin{array}{l}\text { Not recommended for cardiovascular risk assessment } \\
\text { in asymptomatic adults }\end{array}$ & III-C \\
\hline
\end{tabular}

additive value in combination with hs-CRP for identification of higher risk persons ${ }^{12}$. The guideline panels did give $\mathrm{LpPla}_{2}$ a class IIb level of evidence $\mathrm{B}$ recommendation for measurement in those at intermediate risk ${ }^{2}$.

B-type natriuretic peptides (BNP) have also been shown to be positively associated with CVD risk both in persons with and without existing CVD from large meta-analyses ${ }^{13}$, with an overall hazard ratio (HR) of 2.8 comparing those in the highest vs. lowest tertile; however, there are only very modest improvements in discrimination as measured by the C-statistic have been noted, and the ACCF/AHA panel did not recommend (Class III) its measurement for $\mathrm{CHD}$ risk assessment in asymptomatic adults ${ }^{2}$.

It is possible that a multimarker approach utilizing biomarkers representing complementary, but different pathologies may be practical in the future and numerous groups are trying to identify the "cocktail" of biomarkers that will serve to significantly enhance risk reclassification. For example, such a combination of biomarkers might involve inflammation, myocyte necrosis, hemodynamic stress, accelerated atherosclerosis, and vascular damage. An example from the Framingham Heart Study utilizing five distinct biomarkers (BNP, C-reactive protein, urine albumin/creatinine, homocysteine, and renin) shows an index consisting of the biomarkers to be independently associated with risk of CVD events; however, only a very modest improvement in C-statistic was observed $^{14}$. Some other prospective studies, such as in older adults documented a significant improvement in Cstatistic from adding troponin, NT-pro BNP, cystatin C, and C-reactive protein to risk factors (C-statistic improvement from 0.67 to $0.77, p<0.001)(15)$, as well as the Belfast PRIME cohort showing troponin, NT-pro BNP, and C-reactive protein together to significantly improve discrimination for predicting events ( $\mathrm{C}$-statistic improvement from 0.67 to $0.70, p<0.001)^{16}$.

While somewhat obvious, but poorly documented in the medical history, a premature family history of CHD is strongly associated with future risk and a careful evaluation of family history in all first degree relatives is recommended (I-B); however, genomic screening, despite its popularity, as failed to be proven to provide incremental predictive utility for CVD events over standard risk assessment and is not recommended (III-C). Modest recommendations, however, are made for the assessment of $\mathrm{HbA1C}$ in persons without diabetes (Ila-B), as well as urinary albumin excretion, especially in those with hypertension or diabetes (Ilb-B) ${ }^{2}$. 


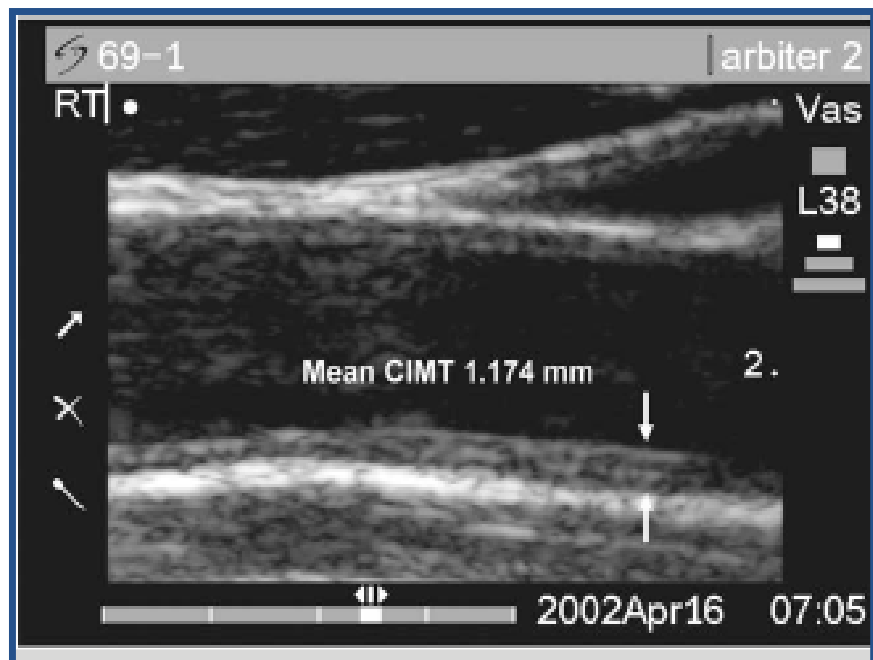

Figure 5. Example of carotid B-mode ultrasonography for assessment of carotid intimal media thickness

\section{Subclinical CVD assessment methods}

Screening tools have been developed for evaluating subclinical CVD in just about every part of the body, ranging from carotid ultrasound to aortic and carotid MRI, coronary calcium screening by $\mathrm{CT}$, ankle brachial index for peripheral artery disease, and brachial artery reactivity and radial tonometric techniques for assessing endothelial function (Figure 4). We will review the principal screening modalities (namely carotid ultrasound, anklebrachial index, and coronary calcification screening) that have the greatest evidence base for cardiovascular risk assessment.

Carotid Ultrasonography. Probably the most established method for examining subclinical atherosclerosis is carotid B-mode ultrasound (Figure 5). It is noninvasive without radiation and of moderate cost and there are numerous clinical trials that have used this as a surrogate endpoint for examining effects of therapeutic interventions such as lipid-lowering on retarding progression of atherosclerosis. Prior studies have shown increased levels of carotid IMT can occur at a relatively early age (e.g., adolescence), thus this technique has the ability to detect at a fairly young age persons who are at potential future risk for CVD events. While the accuracy of assessments of carotid intimal media thicknesses (IMT) depends on

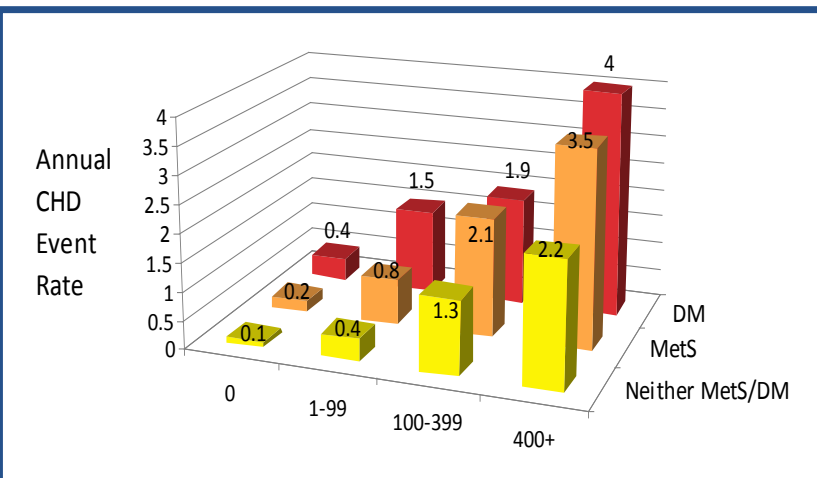

Figure 7. Stratification of CHD risk by coronary calcium levels in persons with and without metabolic syndrome and diabetes. Adapted from Malik et al. (24).

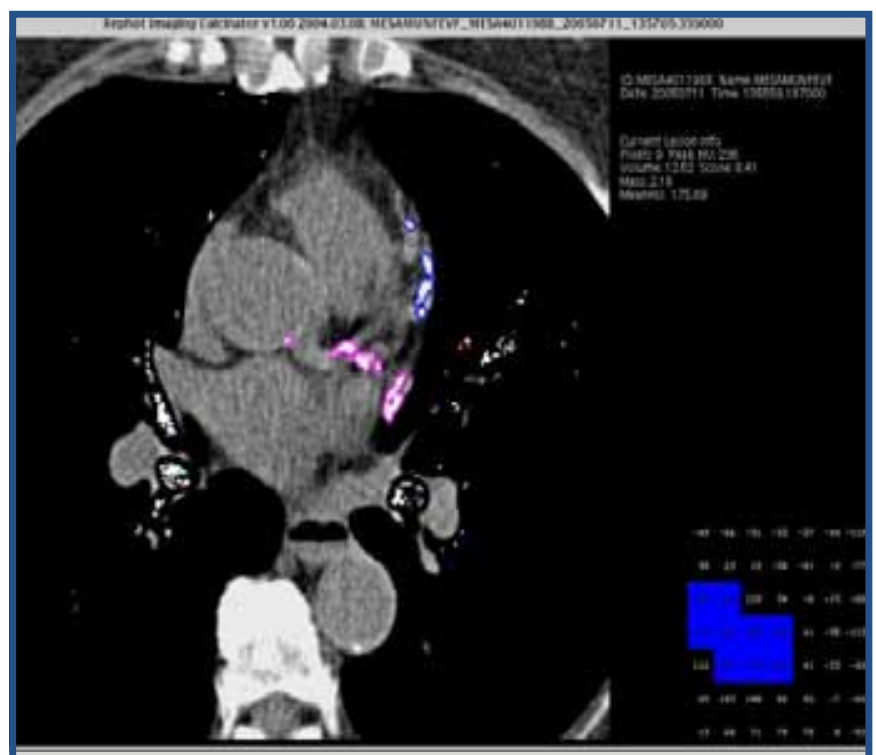

Figure 6. Example of coronary calcium evaluation by computed tomography

the operator, easier more automated devices are being developed which will make its assessment more standardized and applicable to the office-based practitioner. The ACCF/AHA guidelines give IMT measurement a class Ila level of evidence $B$ recommendation in asymptomatic intermediate risk persons ${ }^{2}$. Increased carotid IMT has long been shown to be associated with greater CVD event risk, such as shown by the Cardiovascular Health Study in

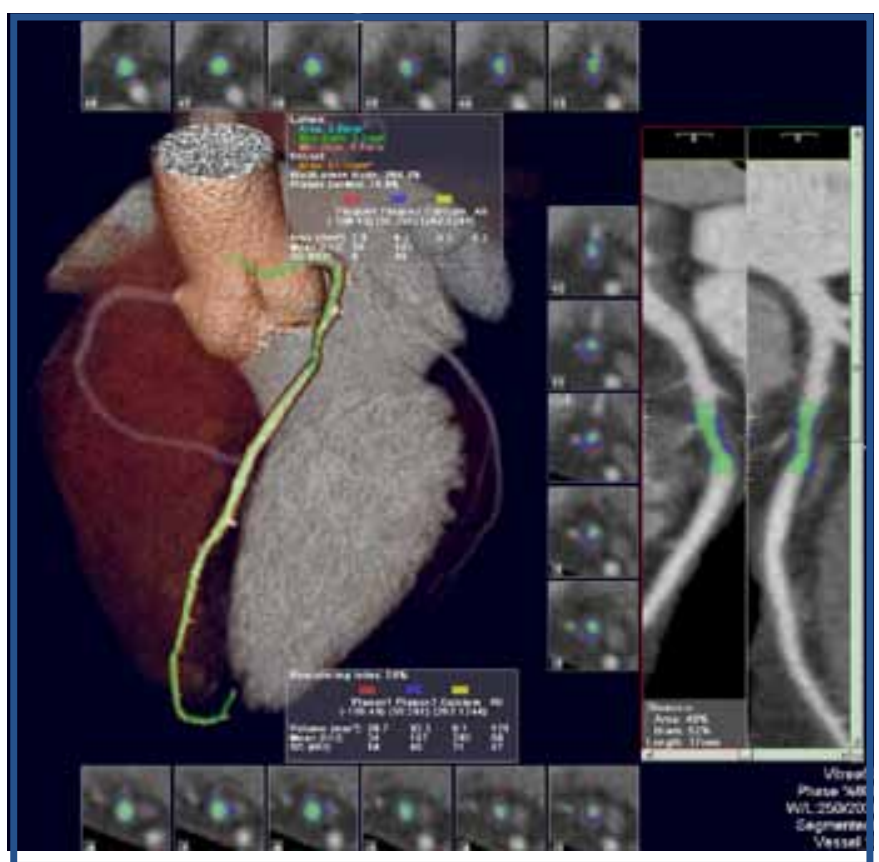

Figure 8. 3D vessel probe of the Left Main and LAD co ronary artery from $C T$ angiography. Curved MPR images are automatically rendered and quantify this LAD lesion at $48 \%$ diameter stenosis. SUREPlaque software is used to determine plaque burden and a vessel remodeling index at this lesion. Images courtesy of Courtesy of Toshiba America Medical Systems and Vital Images SUREPlaque and University of California Irvine, Cardiac CT Center. 
the elderly, where among those in the $5^{\text {th }}$ quintile for carotid IMT, one quarter had suffered a MI or stroke within 7 years ${ }^{17}$. More recently, the Atherosclerosis Risk in Communities study demonstrated the combined importance of both carotid IMT as well as carotid plaques for prediction of CHD events; at each level of carotid IMT, there was added prediction offered by the presence of carotid plaques ${ }^{18}$. The combination of both was able to reclassify $23 \%$ of individuals over traditional risk factors.

Ankle Brachial Index. Measurement of subclinical peripheral arterial disease can help identify persons more likely to have vascular disease in other areas as well as increased CVD risk. Ankle brachial index (ABI) measurement involves a simple Doppler tool and is completely noninvasive, with the ratio of the higher of the systolic BP measures from each ankle forming the numerator for the left and right $A B I$ and the higher of the systolic $B P$ measures taken in each arm being the denominator. $A n A B I$ $<0.9$ is diagnostic of peripheral arterial disease. Studies such as the Cardiovascular Health Study have shown the lower the $A B I$ the worse the survival, with $<80 \%$ of subjects alive after 6 years among those with an $A B I<0.9^{19}$. The more recently reported $\mathrm{ABI}$ Collaboration showed that compared to a reference group of 1.1-1.2, those with an $A B I<1.0$ were at significantly higher risk of total mortality, even those in the borderline $0.9-<1.0$ range, there was nearly a two-fold increase in the risk of mortality ${ }^{20}$. From this study, $19 \%$ of men and $38 \%$ of women were reclassified in their risk category from the addition of $A B I$. The test has received a class Ila level of evidence $B$ recommendation for assessment of CVD risk in intermediate risk individuals; the rate for positive tests is quite low, however, until after the age of 60; thus the test is most appropriate for screening older individuals for peripheral arterial disease, which if present, is clearly known to be associated with disease in other vascular beds.

Coronary Artery Calcium. Coronary artery calcium (CAC) measured by computed tomography (Figure 6) has established itself as the most potent subclinical disease predictor of future CVD events. Of the subclinical disease measures tested, CAC is unquestionably of greatest strength for the prediction of future CHD events. The extent of CAC correlates with overall atherosclerotic burden, although the greatest CAC deposits may not necessarily be present where the tightest stenosis are located and not all atherosclerotic lesions necessary contain CAC; CAC has often been referred as the "tip of the iceberg", identifying those with significant underlying atherosclerotic burden that may not yet be calcified. Moreover, persons without CAC have been considered to have at least a five year "warranty" from having future CHD events ${ }^{21}$. While numerous "commercial" scanning cohorts have shown a direct relation between CAC scores and future CHD events, the Multiethnic Study of Atherosclerosis (MESA) was the first population-based prospective study to demonstrate this with successively higher rates of $\mathrm{CHD}$ events associated with greater CAC scores ${ }^{22}$. Those with a CAC score $>300$ compared to 0 had nearly a 7-fold greater risk of major CHD events and 10-fold greater risk of any CHD events. Moreover, incremental discrimination from higher C-statistics were noted in the four major ethnic groups included in MESA over and above standard risk factors. Examination of clinical utility has overall shown $23 \%$ of persons with events to be reclassified as high risk and $13 \%$ without events reclassified as low risk ${ }^{23}$. More recently, we demonstrated CAC scoring to stratify risk in those with metabolic syndrome and diabetes; there was a 10-fold or greater gradient in risk of CHD events from those without CAC ( $0.4 \%$ per year) to those with CAC scores of 400 or greater (4\% per year), thus demonstrating that diabetes is not universally a CHD risk equivalent but is associated with significant heterogeneity in risk (Figure 7$)^{24}$. More than one-third of our cohort with diabetes had CAC scores of 0 and CHD risk was lower than many persons without DM or MetS; thus, this raises question regarding whether DM is in fact a $\mathrm{CHD}$ risk equivalent. The ACCF/AHA statement has noted with a Class Ila level of evidence $B$ recommendation that measurement of CAC is reasonable for cardiovascular risk assessment in asymptomatic adults at intermediate risk, as well as at low to intermediate risk based on $6-10 \%$ (class IIb), but not in those at low risk. However, those with diabetes aged $>40$ are also appropriate for CAC measurement (Class Ila level of evidence $B)^{2}$. We have also demonstrated progression of CAC has also recently been demonstrated to be independently associated with future CHD event risk $^{25}$; however, guidelines thus far have not endorsed repeat CAC scanning for stratification of risk or treatment ${ }^{26}$

We showed the identification of CAC has also been shown to be related in an observational study to be related to the subject's greater likelihood of practicing preventive behaviors, such as starting aspirin or cholesterol medicine, losing weight, and seeing a doctor, with the extent of calcification also shown to be related to the likelihood of certain behaviors ${ }^{27}$. More recently, in the Early Identification of Subclinical Atherosclerosis by Noninvasive Imaging Research (EISNER) prospective randomized trial, where over 2,000 asymptomatic subjects were randomized 2:1 to calcium scanning or not to scanning, those who received scanning showed no increase in their Framingham risk score 4 years later, compared to an increase in the risk score seen among those not received scanning ${ }^{28}$. Also, in a very recent report, the greater the lifestyle score (number of healthy lifestyle behaviors), the less the incidence or progression of CAC seen from serial CAC scanning in MESA ${ }^{29}$.

Some have argued that CAC testing might increase the utilization of other testing, but this has not been proven. In fact, the Eisner Study of subjects randomized to CAC testing or no testing showed no significant difference in the incidence of downstream testing over 4 years of follow-up ${ }^{28}$. In addition, the radiation dose from CAC scanning has been shown to be similar to that of a mammogram or a long distance air flight.

Further, CAC scanning can help identify those most likely to have a positive nuclear myocardial perfusion test; the likelihood of such a test being positive is quite low unless CAC scores exceed $400^{30}$. Among those with diabetes or metabolic syndrome, a threshold CAC score of 100 is seen to identify those with an increased likelihood of a positive nuclear study ${ }^{31}$. Thus, CAC scanning may serve as a useful gatekeeper for identifying those most likely to benefit from nuclear myocardial perfusion testing. 
There has also been interest in whether CAC testing can help identify those who may or may not benefit from statin therapy. In the Jupiter eligible population from MESA (e.g., LDL-C $<130$, hs CRP $>2$, and no DM) it was shown that only $25 \%$ of subjects had a CAC $>100$ and when the Jupiter relative risk reduction was applied to the CHD event rates observed in this group, it would take only 24 persons treated with a statin to prevent one event; however, in the $27 \%$ with CAC $1-100$, the number need to treat (NNT) was 94 and in the remainder with $C A C=0$, the NNT was $549^{32}$. Thus, CAC testing was able to identify persons with significant subclinical atherosclerosis who had a higher baseline CHD risk and who would be most likely to benefit from statin therapy.

When all the noninvasive screening modalities are examined together in MESA, a recent report shows CAC to be by far the strongest predictor and is associated with the greatest incremental value improvement by the $\mathrm{C}$ statistic over Framingham Risk Score ${ }^{33}$.

CT Angiography and Non-Calcified Plaque. CT Angiography has paved the way for identification of non-calcified and vulnerable plaque characteristics (Figure 8) with quantification that compares well to that of intravascular ultrasound ${ }^{34}$; certain feature such as positive remodeling, spotty calcification, and low attenuation non-calcified plaque $<30 \mathrm{HU}$ have been shown to have a high predictive value for culprit plaques associated with acute coronary syndrome ${ }^{35}$ and in a subsequent study involving follow-up of 1059 patients who underwent CT angiography, those with at least two of these features were significantly more likely to develop future acute coronary syndrome ${ }^{36}$. However, due to the radiation and contrast enhancement required, the ACCF/AHA recommendations still do not indicate it for CVD risk assessment in asymptomatic adults ${ }^{2}$. Nevertheless, the number of diseased vessels from CT angiography has been shown to be a strong predictor of prognosis ${ }^{37}$, although information provided by CT angiography does not appear to add further information to prediction of $\mathrm{CHD}$ events over that of $\mathrm{CAC}^{38}$.

\section{References}

1. Kannel WB, Dawber TR, Kagan A, et al. Factors of risk in development of coronary heart disease-six year follow-up experience: the Framingham Study. Ann Intern Med 1961; 55: 33-50.

2. Greenland P, Alpert JS, Beller GA, et al. 2010 ACCF/AHA guideline for assessment of cardiovascular risk in asymptomatic adults: executive summary: a report of the American College of Cardiology Foundation/American Heart Association Task Force on Practice Guidelines. Circulation 2010;122:2748-2764.

3. Kannel WB, D'Agostino RB, Sullivan L, Wilson PW. Concept and usefulness of cardiovascular risk profiles. Am Heart J. 2004;148:16-26.

4. Wilson PW, D'Agostino RB, Levy D, Belanger AM, Silbershatz $H$, Kannel WB. Prediction of coronary heart disease using risk factor categories. Circulation 1998;97: 1837-47.

5. Expert Panel on Detection, Evaluation, and Treatment of High Blood Cholesterol in Adults. Executive Summary of the Third Report of the National Cholesterol Education Program (NCEP) Expert Panel on Detection, Evaluation, and Treatment of High Blood Cholesterol in Adults (Adult Treatment Panel III). JAMA 2001; 285: 2486-2497.

6. D'Agostino RB Sr, Vasan RS, Pencina MJ, Wolf PA, Cobain M, Massaro JM, Kannel WB. General cardiovascular risk profile for use in primary care: the Framingham Heart Study. Circulation 2008; 117: 743-753.
7. Marma AK, Berry JD, Ning H, Persell SD, Lloyd-Jones DM. Distribution of 10-year and lifetime predicted risks for cardiovascular disease in US adults: findings from the National Health and Nutrition Examination Survey 2003 to 2006. Circ CardiovascQual Outcomes 2010; 3:8-14.

8. Wilkins JT, Ning H, Berry J, Zhao L, Dyer AR, Lloyd-Jones DM. Lifetime risk and years lived free of total cardiovascular disease. JAMA 2012;308:1795-1801.

9. Redberg RF, Vogel RA, Criqui MH, Herrington DM, Lima JA, Roman MJ. 34 ${ }^{\text {th }}$ Bethesda Conference: Task force \#3--What is the spectrum of current and emerging techniques for the noninvasive measurement of atherosclerosis? J Am CollCardiol 2003;41:1886-1898.

10. Pencina MJ, D'Agostino RB Sr, Steyerberg EW. Extensions of net reclassification improvement calculations to measure usefulness of new biomarkers. Stat Med 2011;30:11-21.

11. Ridker PM. Clinical application of C-reactive protein for cardiovascular disease detection and prevention. Circulation 2003;107:363369.

12. Thompson A, Gao P, Orfei L, et al. Lp-Pla2 Studies Collaboration: Lipoprotein-associated phospholipase $A(2)$ and risk of coronary disease, stroke, and mortality: collaborative analysis of 32 prospective studies. Lancet 2010;375:1536-1544.

13. Di Angelantonio E, Chowdhury R, Sarwar N, et al. B-type natriuretic peptides and cardiovascular risk: systematic review and meta-analysis of 40 prospective studies. Circulation. 2009;120: 2177-2187.

14. Wang TJ, Gona P, Larson MG, et al. Multiple biomarkers for the prediction of first major cardiovascular events and death. N Engl J Med 2006;355:2631-2639.

15. Zethelius B, Berglund L, Sundström J, et al. Use of multiple biomarkers to improve the prediction of death from cardiovascular causes. N Engl J Med 2008;358:2107-2116.

16. Blankenberg S, Zeller T, Saarela O,et al; MORGAM Project. Contribution of 30 biomarkers to 10 -year cardiovascular risk estimation in 2 population cohorts: the MONICA, risk,genetics, archiving, and monograph (MORGAM) biomarker project. Circulation 2010;121:2388-2397.

14. O'Leary DH, Polak JF, Kronmal RA, Manolio TA, Burke GL, Wolfson SK Jr. Carotid-artery intima and media thickness as a risk factor for myocardial infarction and stroke in older adults. Cardiovascular Health Study Collaborative Research Group. N Engl J Med 1999;340:14-22.

15. Nambi V, Chambless L, Folsom AR, et al. Carotid intima-media thickness and presence or absence of plaque improves prediction of coronary heart disease risk: the ARIC (Atherosclerosis Risk In Communities) study. J Am Coll Cardiol 2010; 55: 1600-1607.

16. Newman AB, Shemanski L, Manolio TA, et al. Ankle-arm index as a predictor of cardiovascular disease and mortality in the Cardiovascular Health Study. The Cardiovascular Health Study Group. Arterioscler Thromb Vasc Biol 1999;19:538-545.

17. Ankle Brachial Index Collaboration, Fowkes FG, Murray GD, Butcher l, et al. Ankle brachial index combined with Framingham Risk Score to predict cardiovascular events and mortality: a meta-analysis. JAMA 2008; 300: 197-208.

18. Min JK, Lin FY, Gidseg DS, Weinsaft JW, Berman DS, Shaw LJ, Rozanski A, Callister TQ. Determinants of coronary calcium conversion among patients with a normal coronary calcium scan: what is the "warranty period" for remaining normal? J Am Coll Cardiol 2010 Mar 16;55(11):1110-1117.

19. Detrano R, Guerci AD, Carr JJ, et al. Coronary calcium as a predictor of coronary events in four racial or ethnic groups. N Engl J Med 2008;358:1336-1345.

20. Polonsky TS, McClelland RL, Jorgensen NW, et al. Coronary artery calcium score and risk classification for coronary heart disease prediction. JAMA 2010; 303: 1610-1616.

21. Malik S, Budoff MJ, Katz R, et al. Impact of subclinical atherosclerosis on cardiovascular disease events in individuals with metabolic syndrome and diabetes: the multi-ethnic study of atherosclerosis. Diabetes Care 2011;34:2285-2290.

22. Budoff MJ, Young R, Lopez VA, et al. Progression of coronary calcium and incident coronary heart disease events: The Multi-Ethnic Study of Atherosclerosis. J Am Coll Cardiol 2013; 61: 1231-1239.

23. Budoff MJ, Achenbach S, Blumenthal RS, et al. Assessment of coronary artery disease by cardiac computed tomography: a scientific statement from the American Heart Association Committee on Car- 
diovascular Imaging and Intervention, Council on Cardiovascular Radiology and Intervention, and Committee on Cardiac Imaging, Council on Clinical Cardiology. Circulation 2006;114:1761-1791.

24. Wong ND, Detrano RC, Diamond G, et al. Does coronary artery screening by electron beam computed tomography motivate healthy lifestyle behaviors? Am J Cardiol 1996; 78: 1220-1223.

25. Rozanski A, Gransar H, Shaw LJ, et al. Impact of Coronary Artery Calcium Scanning on Coronary Risk Factors and Downstream Testing: The EISNER (Early Identification of Subclinical Atherosclerosis by Noninvasive Imaging Research) Prospective Randomized Trial. J Am Coll Cardiol 2011; 57:1622-1632.

26. Ahmed HM, Blaha MJ, Nasir K, et al. Low-risk lifestyle, coronary calcium, cardiovascular events, and mortality: Results from MESA. Am J Epidemiol 2013; 178:12-21.

27. Berman DS, Wong ND, Gransar $\mathrm{H}$, et al. Relationship between stress-induced myocardial ischemia and atherosclerosis measured by coronary calcium tomography. J Am Coll Cardiol 2004;44:923930.

28. Wong ND, Rozanski A, Gransar H, et al. Metabolic syndrome and diabetes are associated with an increased likelihood of inducible myocardial ischemia among patients with subclinical atherosclerosis. Diabetes Care 2005;28:1445-1450.

29. Blaha MJ, Budoff MJ, DeFillipis AP, et al. Associations between Creactive protein, coronary artery calcium, and cardiovascular events: implications for the JUPITER population from MESA, a population-based cohort study. Lancet 2011; 378: 684-692.
30. Yeboah J, McClelland RL, Polonsky TS, et al. Comparison of novel risk markers for improvement in cardiovascular risk assessment in intermediate-risk individuals. JAMA 2012; 308: 788-795.

31. Nakazato R, Shalev A, Doh JH, Koo BK, Dey D, Berman DS, Min JK. Quantification and characterisation of coronary artery plaque volume and adverse plaque features by coronary computed tomographic angiography: a direct comparison to intravascular ultrasound. Eur Radiol 2013;23:2109-2117.

32. Motoyama S, Kondo T, Sarai M, et al. Multislice computed tomographic characteristics of coronary lesions in acute coronary syndromes. J Am Coll Cardiol 2007; 50: 319-326.

33. Motoyama S, Sarai $\mathrm{M}$, Harigaya $\mathrm{H}$, et al. Computed tomographic angiography characteristics of atherosclerotic plaques subsequently resulting in acute coronary syndrome. J Am Coll Cardiol 2009;54(1):49-57.

34. Hulten E, Villines TC, Cheezum MK, et al. CONFIRM Investigators. Usefulness of coronary computed tomography angiography to predict mortality and myocardial infarction among Caucasian, African and East Asian ethnicities (from the CONFIRM [Coronary CT Angiography Evaluation for Clinical Outcomes: An International Multicenter] Registry). Am J Cardiol 2013;111:479-485.

35. Cho I, Chang HJ, Sung JM, et al. CONFIRM Investigators. Coronary computed tomographic angiography and risk of all-cause mortality and nonfatal myocardial infarction in subjects without chest pain syndrome from the CONFIRM Registry (coronary CT angiography evaluation for clinical outcomes: an international multicenter registry). Circulation 2012;126:304-313. 